\title{
PILHAS A COMBUSTÍVEL DE ÓXIDO SÓLIDO: MATERIAIS, COMPONENTES E CONFIGURAÇÕES
}

\author{
Roberto Salgado Amado, Luiz Fernando Brum Malta, Francisco M. S. Garrido e Marta Eloisa Medeiros*
}

Departamento de Química Inorgânica, Instituto de Química, Universidade Federal do Rio de Janeiro, Cidade Universitária, Ilha do Fundão, 21945-970 Rio de Janeiro - RJ, Brasil

Recebido em 19/7/05; aceito em 22/2/06; publicado na web em 30/8/06

\begin{abstract}
SOLID OXIDE FUEL CELLS: MATERIALS, COMPONENTS AND CONFIGURATIONS. In this paper the current status of fuel cells is described with particular emphasis on high $\left(\mathrm{T}>800^{\circ} \mathrm{C}\right)$ and intermediate $\left(\mathrm{T}<800^{\circ} \mathrm{C}\right)$ temperature solid oxide fuel cells. Also the importance of the fuel cell technology is shown. Reviewed are the fundamental features, the basic principles, types of fuel cell, fabrication methods, cell configurations and the development of components (cathodes, anodes, electrolytes, interconnect) and materials.
\end{abstract}

Keywords: fuel cells; energy; SOFC.

\section{INTRODUÇÃO}

O mundo tem-se voltado, nos últimos anos, para a discussão dos problemas econômicos e ambientais decorrentes da crescente dependência dos combustíveis fósseis como fonte primária para geração de energia. Grande atenção tem sido dada ao problema do aquecimento global, ocasionado, principalmente, pela emissão de gases decorrentes da queima desses combustíveis. Este fato tem provocado um grande interesse em pesquisas voltadas a formas alternativas de produção de energia elétrica, com especial atenção para aquelas provenientes de fontes renováveis. Destas novas tecnologias alternativas podem ser citadas: micro-hidráulicas, microturbinas, uso de biomassa, energia eólica, células fotovoltaicas, sistemas geotérmicos e pilhas a combustível. Dentre estas, as pilhas a combustível destacam-se como uma tecnologia bastante promissora ${ }^{1-4}$.

Pilha a combustível é um dispositivo eletroquímico, que realiza a conversão de energia gerada por uma reação eletroquímica em energia elétrica, sendo um método altamente eficiente de geração de eletricidade e, em alguns casos, de calor. Os combustíveis mais utilizados são hidrogênio e substâncias que através de reforma gerem hidrogênio, como gás natural, hidrocarbonetos, metanol e biogás.

A partir de 1970 vários tipos de pilhas foram montados, inclusive com algumas empresas já testando como combustível o gás natural. Mas foi na década de 80 que ocorreu um avanço mais intenso desta tecnologia, tornando possível a utilização, ainda em condições experimentais, de pilhas a combustível em veículos particulares e de transporte coletivo, assim como na geração de energia elétrica em larga escala. Atualmente, seu emprego pode ser visto em diversas finalidades, por ex., em automóveis e ônibus, montados nos Estados Unidos, na Alemanha, no Canadá e Japão, onde são utilizadas pilhas a combustível com capacidade de geração de cerca de $85 \mathrm{~kW}$ de potência, ou em módulos estacionários montados em Nova York e Tóquio no final da década passada, com geração de 4,8 MW de potência ${ }^{1-4}$.

Desde a criação da primeira pilha a combustível até os dias atuais, o avanço desta tecnologia permitiu o desenvolvimento de vários tipos de dispositivos para gerar energia de forma mais limpa, ou seja, minimizando os impactos ambientais ${ }^{1-6}$.

Pilhas a combustível podem ajudar a diminuir a dependência em combustíveis fósseis e diminuir a emissão de gases do efeito

*e-mail:martam@iq.ufrj.br estufa na atmosfera, uma vez que seu desenvolvimento tecnológico atual permite um aumento na eficiência da conversão da energia química dos combustíveis em energia elétrica, se comparada com a máquina a vapor. Usando hidrogênio puro como combustível este dispositivo somente produz água, eliminando assim todas as outras emissões. Embora seja possível produzir energia pelo vento, pela água e pelo sol, essas fontes renováveis não são suficientes para cobrir toda a base elétrica, devido à disponibilidade irregular. Entretanto, a combinação dessas fontes com a pilha a combustível pode ser uma opção para o futuro da geração de energia ${ }^{1-4}$.

Neste trabalho serão discutidos inicialmente alguns conceitos fundamentais relacionados às pilhas a combustível e, a seguir, serão abordados aspectos relacionados especificamente às pilhas do tipo óxido sólido. Artigos recentes, em português, com abordagens introdutórias e mais abrangentes sobre o tema pilhas a combustível foram agrupados na referência 3.

\section{PRINCÍPIOS BÁSICOS DE UMA PILHA A COMBUSTÍVEL}

A característica chave da pilha a combustível é sua alta eficiência de conversão de energia, medida pelo quociente gás combustível/energia elétrica gerada. Por converter energia química diretamente em elétrica, sua eficiência não está sujeita às limitações dos processos térmicos ${ }^{1,3,5}$.

O início dos estudos de pilhas a combustível data de 1839, quando Willian Grove ${ }^{7}$ explorou a energia elétrica produzida por reações químicas simples. Verificou-se na ocasião que elétrons passavam por um circuito externo acoplado à pilha a combustível, ou seja, que a energia química era transformada em energia elétrica.

A pilha, então, produzida utilizava uma solução diluída de ácido sulfúrico como eletrólito, gás oxigênio como agente oxidante e gás hidrogênio como combustível ${ }^{1}$. As reações envolvidas nesse dispositivo são as seguintes:

Reação anódica: $\mathrm{H}_{2(\mathrm{~g})} \rightarrow 2 \mathrm{H}^{+}+2 \mathrm{e}^{-}$

Reação catódica: $1 / 2 \mathrm{O}_{2(\mathrm{~g})}+2 \mathrm{e}^{-}+2 \mathrm{H}^{+}{ }_{(\mathrm{aq})} \rightarrow \mathrm{H}_{2} \mathrm{O}_{(\mathrm{l})}$

A variação na energia livre de Gibbs $\left(\Delta \mathrm{G}^{\circ}\right)$ de uma reação química é relacionada ao potencial de equilíbrio, $\mathrm{E}^{\mathrm{o}}$, da pilha com os reagentes nos estados padrão, pela Equação ${ }^{1,3,8}$ : 
$\Delta \mathrm{G}^{\mathrm{o}}=-n F \mathrm{E}^{\mathrm{o}}$

onde $\mathrm{n}$ é o número de elétrons envolvido na reação, $\mathrm{F}$ é a constante de Faraday, e $\mathrm{E}^{\mathbf{o}}$ é o potencial padrão da pilha, no equilíbrio termodinâmico, na ausência de um fluxo de corrente. Para o caso de uma pilha de hidrogênio/oxigênio a reação global é dada por:

$\mathrm{H}_{2(\mathrm{~g})}+1 / 2 \mathrm{O}_{2(\mathrm{~g})} \rightarrow \mathrm{H}_{2} \mathrm{O}_{(\mathrm{l})} \quad \operatorname{com} \Delta \mathrm{G}^{\mathrm{o}}=-237 \mathrm{~kJ} / \mathrm{mol}$

Com a pilha em equilíbrio sob condições padrão, a $25^{\circ} \mathrm{C}$ e 1 atm, temos que:

$\mathrm{E}^{\mathrm{o}}=-\Delta \mathrm{G}^{\mathrm{o}} / \mathrm{nF}=1,23 \mathrm{~V}$

Quando uma corrente passa pela pilha, sob condições padrão, a voltagem é dada por:

$V=E^{o}-I R-\eta_{A}-\eta_{F}$

onde, I é a corrente que passa pela pilha, $\mathrm{R}$ é a resistência elétrica (associada principalmente com o eletrólito) e $\eta_{\mathrm{A}}$ e $\eta_{\mathrm{F}}$ são as perdas de voltagem por polarização (sobretensão) associadas com o catodo e o anodo, respectivamente. Os mecanismos responsáveis por essas perdas por polarização nos eletrodos e eletrólito são ${ }^{1}$ : polarização química, associada com a energia de ativação das etapas dos processos eletroquímicos que ocorrem nos eletrodos, portanto, está diretamente relacionada com a velocidade das reações eletroquímicas que ocorrem nos eletrodos; polarização por concentração, à medida que os reagentes são consumidos nos eletrodos, pelas reações eletroquímicas, ocorre uma perda de potencial relacionada com a formação de um gradiente de concentração ao redor dos eletrodos, este gradiente está associado com a difusão dos reagentes e dos produtos; polarização Ôhmica ou de resistência (R), relacionada principalmente com as perdas ôhmicas que ocorrem em função da resistência ao fluxo de íons no eletrólito, as resistências ao fluxo de elétrons através dos eletrodos também contribuem para esta polarização.

As estruturas básicas de todas as pilhas a combustível são similares ${ }^{1,3,5}$ (Figura 1): uma pilha consiste de dois eletrodos, separados por um eletrólito e conectados eletricamente a um circuito externo. Os eletrodos são expostos a um combustível ou a um oxidante, por ex., os gases hidrogênio e oxigênio, respectivamente. Os eletrodos devem ter permeabilidade ao gás ou líquido a ser utilizado, ou seja, ter uma estrutura porosa, uma vez que a corrente elétrica gerada pela pilha é proporcional à área útil dos eletrodos. A difusão do gás na estrutura porosa dos eletrodos é complexa e requer considerável otimização para aplicação prática.

Para que uma pilha a combustível apresente um bom desempenho é fundamental que nos eletrodos sejam criadas interfaces entre três fases (reagentes, eletrólito e catalisador). Portanto, os eletrodos, além de condutores eletrônicos, devem: ser porosos para permitir a permeação dos gases até a interface com o eletrólito; apresentar propriedades catalíticas para acelerar as reações eletroquímicas e, ser impermeáveis ao eletrólito, quando este for líquido, para que o eletrólito não invada o eletrodo e impeça o acesso dos gases à zona de reação ${ }^{1}$.

No caso de uma pilha a combustível com eletrólito condutor de íons óxido $\left(\mathrm{O}^{2-}\right)$ (Figura 1), que pode ser uma pilha de alta temperatura $\left(\mathrm{T} \geq 800^{\circ} \mathrm{C}\right)$ ou temperatura intermediária $\left(\mathrm{T}<800^{\circ} \mathrm{C}\right)$, o gás oxigênio é reduzido no catodo, os íons óxido formados entram no eletrólito e são transportados para o anodo, como na Equação:

$\mathrm{O}_{2}+4 \mathrm{e}^{-} \rightarrow 2 \mathrm{O}^{2-}$
No anodo o gás hidrogênio reage de acordo com a Equação:

$\mathrm{H}_{2(\mathrm{~g})} \rightarrow 2 \mathrm{H}^{+}+2 \mathrm{e}^{-}$

Os elétrons fluem pelo circuito externo e no anodo os íons óxido combinam-se com os prótons para formar água:

$\mathrm{O}^{2-}+2 \mathrm{H}^{+} \rightarrow \mathrm{H}_{2} \mathrm{O}$

Se for usada uma pilha a combustível com eletrólito condutor de prótons, geralmente uma pilha de baixa temperatura $(\mathrm{T}<250$ ${ }^{\circ} \mathrm{C}$ ), a água se formará no catodo, pois o gás hidrogênio é oxidado no anodo, os prótons entram no eletrólito e são transportados para o catodo onde se combinam com os íons óxido.

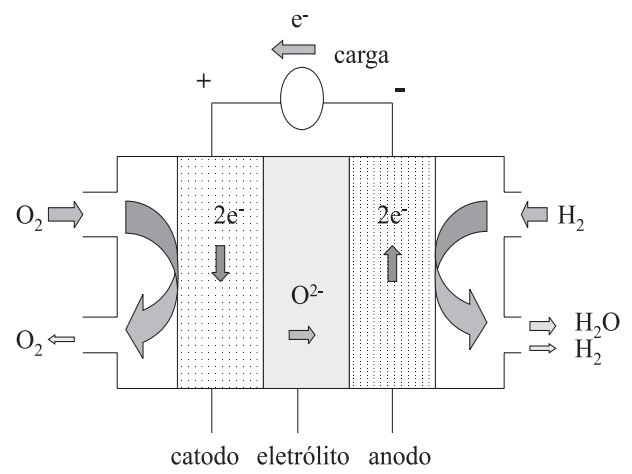

Figura 1. Desenho esquemático de uma pilha a combustível de hidrogênio/ oxigênio do tipo óxido sólido

\section{TIPOS DE PILHAS A COMBUSTÍVEL}

Pilhas a combustível são usualmente classificadas pelo eletrólito empregado, uma vez que este determina a temperatura de operação e o tipo de configuração da pilha. Uma exceção a essa classificação é a DMFC (pilha a combustível com metanol direto), na qual o anodo é alimentado diretamente com metanol, sem a reforma prévia deste ${ }^{6}$. Uma segunda classificação pode ser feita segundo a temperatura de operação. Há assim, dispositivos de temperatura baixa, intermediária e alta. Pilhas a combustível de baixa temperatura $\left(\mathrm{T}<250{ }^{\circ} \mathrm{C}\right)$ são a alcalina (AFC), a de membrana polimérica (PEMFC), a de metanol direto (DMFC) e a de ácido fosfórico (PAFC). As pilhas a combustível de temperaturas intermediária e alta operam aproximadamente entre 500 e $1000{ }^{\circ} \mathrm{C}$ e dois tipos diferentes têm sido desenvolvidos: a pilha a combustível de carbonato fundido (MCFC) e a pilha a combustível de óxido sólido (SOFC) $)^{1,3,5}$. Os diferentes tipos de pilha a combustível são apresentados na Tabela 1.

\section{PILHA A COMBUSTÍVEL DE ÓXIDO SÓLIDO}

Em princípio, seria possível que na condição de equilíbrio uma pilha a combustível convertesse toda a energia livre do processo eletroquímico em energia elétrica, uma vez que não estão envolvidas as perdas características dos processos térmicos de geração de energia. Na realidade, atingir a eficiência máxima ideal $\left(\varepsilon_{\max }\right)$ em uma pilha a combustível (onde: $\varepsilon_{\max }=1-\mathrm{T} \Delta \mathrm{S} / \Delta \mathrm{H}$; sendo $\mathrm{T}=$ temperatura em graus Kelvin, $\Delta \mathrm{S}$ = variação da entropia em Joules/K e $\Delta \mathrm{H}=$ variação da entalpia em Joules) é impossível na prática, uma vez que o desenvolvimento de sobretensão em cada eletrodo e as perdas de potencial no eletrólito, devido a sua resistência elétrica, são inevitáveis ${ }^{1}$. O desafio é saber se é possível desenvolver uma pilha a combustível com eficiência de geração de energia elétrica 
Tabela 1. Características dos diferentes tipos de pilhas a combustível

\begin{tabular}{|c|c|c|c|c|c|c|}
\hline & AFC & PEMFC & DMFC & PAFC & MCFC & SOFC \\
\hline $\begin{array}{l}\text { Temperatura de } \\
\text { operação }\left({ }^{\circ} \mathrm{C}\right)\end{array}$ & $65-220$ & $60-120$ & $60-120$ & $160-220$ & $500-800$ & $500-1000$ \\
\hline Reação anódica & $\begin{array}{l}\mathrm{H}_{2}+2 \mathrm{OH}^{-} \rightarrow \\
2 \mathrm{H}_{2} \mathrm{O}+2 \mathrm{e}^{-}\end{array}$ & $\begin{array}{l}\mathrm{H}_{2} \rightarrow 2 \mathrm{H}^{+} \\
\quad+2 \mathrm{e}^{-}\end{array}$ & $\begin{array}{l}\mathrm{CH}_{3} \mathrm{OH}+\mathrm{H}_{2} \mathrm{O} \rightarrow \\
\mathrm{CO}_{2}+6 \mathrm{H}^{+}+6 \mathrm{e}^{-}\end{array}$ & $\begin{array}{l}\mathrm{H}_{2} \rightarrow 2 \mathrm{H}^{+} \\
\quad+2 \mathrm{e}^{-}\end{array}$ & $\begin{array}{c}\mathrm{H}_{2}+\mathrm{CO}_{3}^{2-} \rightarrow \\
\mathrm{H}_{2} \mathrm{O}+\mathrm{CO}_{2}+2 \mathrm{e}^{-}\end{array}$ & $\begin{array}{l}\mathrm{H}_{2}+\mathrm{O}^{2-} \rightarrow \\
\mathrm{H}_{2} \mathrm{O}+2 \mathrm{e}^{-}\end{array}$ \\
\hline Reação catódica & $\begin{array}{c}1 / 2 \mathrm{O}_{2}+\mathrm{H}_{2} \mathrm{O}+ \\
2 \mathrm{e}^{-} \rightarrow 2 \mathrm{OH}^{-}\end{array}$ & $\begin{array}{c}1 / 2 \mathrm{O}_{2}+2 \mathrm{H}^{+}+ \\
2 \mathrm{e}^{-} \rightarrow \mathrm{H}_{2} \mathrm{O}\end{array}$ & $\begin{array}{l}3 / 2 \mathrm{O}_{2}+6 \mathrm{H}^{+}+ \\
6 \mathrm{e}^{-} \rightarrow 3 \mathrm{H}_{2} \mathrm{O}\end{array}$ & $\begin{array}{c}1 / 2 \mathrm{O}_{2}+2 \mathrm{H}^{+}+ \\
2 \mathrm{e}^{-} \rightarrow \mathrm{H}_{2} \mathrm{O}\end{array}$ & $\begin{array}{l}1 / 2 \mathrm{O}_{2}+\mathrm{CO}_{2}^{+} \\
2 \mathrm{e}^{-} \rightarrow \mathrm{CO}_{3}^{2-}\end{array}$ & $\begin{array}{c}1 / 2 \mathrm{O}_{2}+2 \mathrm{e}^{-} \rightarrow \\
\mathrm{O}^{2-}\end{array}$ \\
\hline Aplicações & \multicolumn{3}{|c|}{$\begin{array}{l}\text { Transportes, militares, espaciais } \\
\text { e sistema de estocagem de energia }\end{array}$} & $\begin{array}{c}\text { Sistemas } \\
\text { de força } \\
\text { descentralizados }\end{array}$ & \multicolumn{2}{|c|}{$\begin{array}{l}\text { Transporte e sistemas } \\
\text { descentralizados }\end{array}$} \\
\hline Utilização & $\begin{array}{l}\text { Plantas pequenas } \\
5-150 \mathrm{~kW}\end{array}$ & $\begin{array}{l}\text { Plantas pequenas } \\
5-250 \mathrm{~kW}\end{array}$ & $\begin{array}{l}\text { Plantas pequenas } \\
5 \mathrm{~kW}\end{array}$ & $\begin{array}{l}\text { Plantas pequenas } \\
\text { e médias } \\
50 \mathrm{~kW}-11 \mathrm{MW}\end{array}$ & $\begin{array}{l}\text { Plantas pequenas } \\
\text { e médias } \\
100 \mathrm{~kW}-2 \mathrm{MW}\end{array}$ & $\begin{array}{l}\text { Plantas pequenas } \\
100 \mathrm{~kW}-250 \mathrm{~kW}\end{array}$ \\
\hline $\begin{array}{l}\text { Íon transportado } \\
\text { no eletrólito }\end{array}$ & $\mathrm{OH}^{-}$ & $\mathrm{H}^{+}$ & $\mathrm{H}^{+}$ & $\mathrm{H}^{+}$ & $\mathrm{CO}_{3}^{2-}$ & $\mathrm{O}^{2-}$ \\
\hline
\end{tabular}

superior a $20-40 \%$, valores normalmente atingidos por processos térmicos de combustão.

Nos últimos anos, várias companhias vêm desenvolvendo pesquisas para produção de pilhas a combustível do tipo eletrólito sólido, baseadas em cerâmicas condutoras de íons óxido, com alta temperatura de operação, ao redor de $1000{ }^{\circ} \mathrm{C}$. Essas pilhas são capazes de utilizar como combustível o hidrogênio, a mistura hidrogênio - monóxido de carbono (produzida na reforma externa de hidrocarbonetos), ou ainda fazer o uso direto de hidrocarbonetos, com ou sem reforma interna ${ }^{5,8}$. Cabe ressaltar que o monóxido de carbono é proibido para pilhas dos tipos PEMFC e PAFC, mais amplamente conhecidas, por ser um veneno para o catalisador (anodo) empregado nessas pilhas, constituído de partículas de platina metálica ${ }^{1}$.

Neste contexto, a utilização de pilhas a combustível de óxido sólido é uma opção bastante interessante, uma vez que elas apresentam algumas vantagens em relação a outros tipos de pilhas, como por ex., são dispositivos inteiramente no estado sólido, permitindo a utilização de processos de fabricação em camadas finas; utilizam metais não preciosos como catalisadores; apresentam um alto valor de eficiência teórica de conversão e, têm a capacidade de co-produção de eletricidade e calor. A sua elevada temperatura de operação favorece a cinética das reações químicas e eletroquímicas e permite a reforma do combustível no interior da própria pilha, sobre o catalisador do anodo ${ }^{5,8}$.

Pilhas a combustível do tipo SOFC apresentam também a vantagem de não utilizarem um meio corrosivo, característico de alguns eletrólitos líquidos, pois empregam um óxido sólido como eletrólito e são, assim, mais estáveis e apresentam maior facilidade de manuseio, se comparadas com as pilhas a combustível de carbonato fundido (MCFC), que podem apresentar problemas de vazamento. Como desvantagens, pode-se citar a alta temperatura de operação, necessária para a obtenção de valores apreciáveis de condutividade iônica do eletrólito, e a menor tolerância a ciclos térmicos. Além disso, é difícil encontrar materiais adequados que apresentem propriedades térmicas compatíveis e estabilidade química e mecânica, para operar a altas temperaturas ${ }^{1,8}$.

As pilhas a combustível do tipo SOFC podem ser classificadas de diferentes maneiras, por ex., através do formato de sua construção. Diferentes formatos de SOFC têm sido desenvolvidos nos últimos anos. O formato tubular, desenvolvido pela SiemensWestinghouse, tem uma estrutura vedada que aumenta sua estabilidade, eliminando a necessidade de um selante para vedá-la. A pilha $^{1,3,8}$ (Figura 2) consiste de um tubo cerâmico, catodo, de manganita de lantânio dopada com $\mathrm{Ca}^{2+}$ ou $\mathrm{Sr}^{2+}$, que é utilizado como suporte. Esses tubos são conformados, prensados e então sinterizados. Os outros componentes da pilha são depositados, sobre esse tubo, na forma de filmes finos, geralmente utilizando-se a técnica de deposição eletroquímica de vapor.

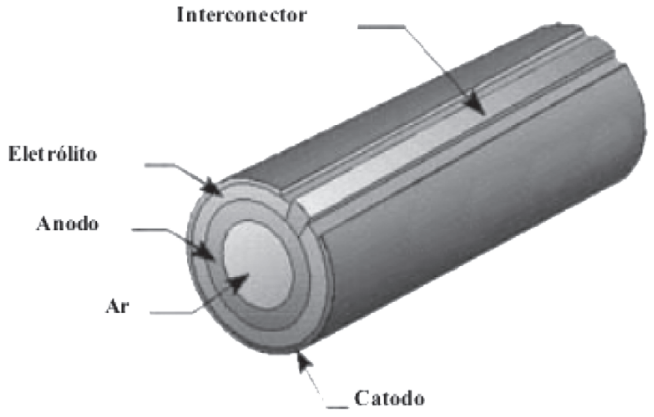

Figura 2. Esquema de uma pilha a combustivel de óxido sólido do tipo tubular fabricada pela Siemens - Westinghouse. Adaptada da ref. 1

Um tipo diferente de formato de SOFC, o planar circular, foi desenvolvido pela empresa Sulzer-Hexis. O HEXIS "1,3,8,9 ("Heat Exchanger Integrated Stack"), Figura 3, pode ser utilizado para pequenas plantas de co-geração de energia. $\mathrm{O}$ interconector, neste caso, serve como um trocador de calor e como um coletor de corrente.

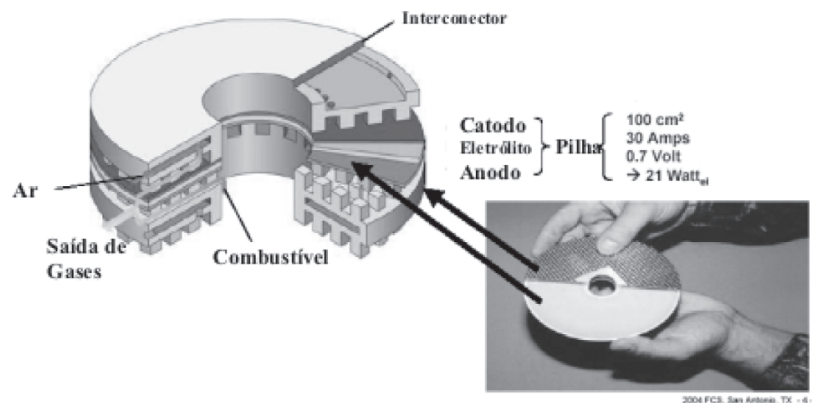

Figura 3. Esquema de uma pilha a combustível de óxido sólido fabricada pela HEXIS. Adaptada da ref. 8

O formato planar retangular ${ }^{8}$ (Figura 4) é, em princípio, o mais eficiente e o mais barato dos três, tendo como desvantagem a fácil ocorrência de trincas, se comparado com as pilhas tubular e planar circular. Os interconectores, ou placas bipolares, são fabricados com 
materiais cerâmicos ou ligas metálicas resistentes ao calor. Entretanto, durante os vários ciclos térmicos da pilha, a diferença do coeficiente de expansão térmica entre os materiais dos interconectores e do eletrólito pode provocar trincas na região de vedação.

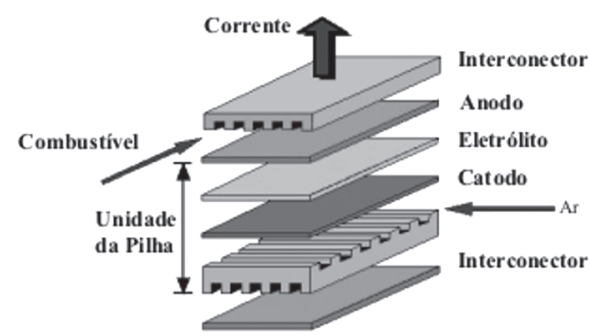

Figura 4. Esquema de uma pilha a combustivel de óxido sólido planar retangular. Adaptada da ref. 8

Outra forma de classificar as pilhas tipo SOFC consiste em separálas como de alta temperatura $\left(\mathrm{T} \geq 800{ }^{\circ} \mathrm{C}\right)$, que podem ser associadas a turbinas à gás para aumentar sua eficiência elétrica, ou de temperatura intermediária $\left(\mathrm{T}<800{ }^{\circ} \mathrm{C}\right)$. Esta última vem sendo intensamente estudada nos últimos anos por apresentar custo menor, maior estabilidade e durabilidade, além de permitir a utilização de interconectores com menor resistência elétrica ${ }^{8,10}$.

As pilhas a combustível podem ainda ser classificadas pelo seu tipo de configuração, podendo ser do tipo bi-câmara ou monocâmara. As pilhas tipo SOFC convencionais, como as descritas anteriormente, consistem de duas câmaras separadas fisicamente por um eletrólito impermeável a gases, sendo que cada uma delas contém um dos eletrodos (catodo ou anodo). O princípio de funcionamento dessas pilhas é baseado na alimentação separada de combustível e ar para o anodo e o catodo, respectivamente. Uma outra configuração de pilha, que recentemente voltou a ser estudada ${ }^{11-14}$, consiste de somente uma câmara, onde o anodo e o catodo são expostos à mesma mistura de combustível e $a^{14}$. Nestas pilhas o anodo tem uma alta atividade catalítica para oxidação do combustível, enquanto que o catodo tem maior atividade eletrocatalítica para redução do oxigênio, resultando assim em uma força eletromotriz entre os dois eletrodos.

Pilhas com configuração monocâmara oferecem duas vantagens principais, se comparadas com as pilhas a combustível convencionais: sua construção é mais simples, porque não precisa de uma separação vedada entre a alimentação do combustível e do ar e, permitem uma diminuição significativa da espessura do eletrólito, o que diminui a resistência ôhmica da pilha devido à redução da separação entre os dois eletrodos ${ }^{11-14}$.

Do ponto de vista tecnológico, destacam-se as seguintes vantagens desta configuração de pilha a combustível: diminuição do custo de manufatura, decorrente da simplificação do projeto; aumento da densidade de potência, em virtude da eliminação de estruturas complexas, volumosas e que agregam peso, como por ex., separadores e selagens; aumento da confiabilidade e vida útil do sistema, em função da sua simplificação e da eliminação das estruturas de vedação interna, sujeitas a trincas e perda de funcionalidade ${ }^{11-14}$.

Em virtude destas vantagens tecnológicas as pilhas do tipo monocâmara, juntamente com o conceito de pilha de conversão direta de hidrocarbonetos ${ }^{5,8,15-18}$, transformaram-se em alvo de considerável interesse por parte de vários laboratórios envolvidos no desenvolvimento e fabricação de pilhas a combustível. Recentemente foi demonstrado que pilhas monocâmara podem ser montadas com uma configuração do tipo micro pilha a combustível termicamente auto sustentada, o que pode no futuro permitir, inclusive, que elas venham a ser utilizadas como fonte de energia do tipo portátil. Entretanto, as pilhas SOFC tipo monocâmara ainda não foram testadas por períodos longos de operação e nem foram fabricados empilhamentos com esta concepção ${ }^{11-14,17}$; portanto, este tipo de pilha ainda depende de grande quantidade de estudos para poder ser aplicada na prática.

Os principais componentes, necessários para montagem de uma SOFC, variam dependendo do projeto de construção utilizado, mas, de modo geral, podemos dividi-los em: interconector, catodo, anodo e eletrólito. A seguir serão relatadas as principais características destes componentes, assim como os materiais utilizados em cada caso. Uma revisão recente, em português, abordou de forma detalhada os materiais cerâmicos utilizados em pilhas do tipo SOFC ${ }^{19}$; em função disso, neste trabalho serão discutidos apenas alguns exemplos de materiais, procurando apresentar de forma didática certos aspectos relacionados à modulação das propriedades importantes para aplicação desses materiais.

\section{Interconector ${ }^{8,10,19}$}

O interconector, ou placa bipolar é o componente que apresenta as maiores exigências e deve possuir: alta condutividade eletrônica; estabilidade em ambas atmosferas, oxidante e redutora, na temperatura de operação; baixa permeabilidade para oxigênio e hidrogênio, para minimizar a combinação direta do oxidante e combustível durante a operação da pilha; expansão térmica próxima do eletrólito e dos eletrodos e, ser quimicamente inerte com os eletrodos, eletrólito e o material de contato elétrico.

Os materiais cerâmicos mais usados são as cromitas de lantânio $\left(\mathrm{LaCrO}_{3}\right)$, com estrutura tipo perovskita, dopadas com íons de metais alcalinos terrosos (cálcio, magnésio ou estrôncio). Também são descritas dopagens com íons de metais de transição, como cobalto, cobre, ferro, níquel e vanádio; entretanto, estes dopantes são geralmente utilizados juntamente com cálcio e estrôncio, com o objetivo de refinar as propriedades da cromita. Esses materiais possuem uma boa condutividade eletrônica (são condutores do tipo p) e um coeficiente de expansão térmica similar ao da zircônia, entretanto, apresentam alto custo de fabricação e estabilidade química apenas moderada. Atualmente, o emprego de interconectores de materiais metálicos, como níquel, ligas de cromo ou de ferro, ou ainda, um metal/cermet como o $\mathrm{CrFe} / \mathrm{Y}_{2} \mathrm{O}_{3}$ vem mostrando um melhor desempenho em pilhas a combustível de óxido sólido de temperatura intermediária, especialmente para $\mathrm{T}<700^{\circ} \mathrm{C}$, onde os problemas de corrosão são minimizados ${ }^{8,10}$.

\section{Catodo}

O eletrodo catódico em um dispositivo SOFC deve possuir as seguintes características ${ }^{1,5,8}$ : alta condutividade eletrônica; estabilidade química e estrutural; expansão térmica compatível com o eletrólito; compatibilidade e reatividade mínima com o eletrólito e o interconector, com os quais o eletrodo fica em contato e, porosidade suficiente para facilitar o transporte de oxigênio para a fase gasosa na interface eletrodo/eletrólito.

Para satisfazer estas necessidades, os eletrodos são confeccionados com materiais cerâmicos com estrutura cristalina do tipo perovskita e com íons lantanídeos na sua composição, uma vez que esses materiais apresentam alta condutividade eletrônica e alta atividade catalítica para redução do oxigênio ${ }^{5,8,19-22}$. Dessa classe de materiais destacam-se as manganitas, cobaltitas e ferritas de latânio dopadas. A dopagem nesses materiais é feita com o objetivo de otimizar as propriedades de condução eletrônica e iônica, minimizar a reatividade com o eletrólito (geralmente YSZ) e melhorar a compatibilidade do coeficiente de expansão térmico (CET) 
com os outros componentes da pilha. Na Tabela 2 são apresentados os principais exemplos de materiais de catodo $^{8,19-22}$.

Tabela 2. Sigla, composição e condutividade eletrônica de catodos tipo perovskita usados em pilha a combustível do tipo óxido sólido

\begin{tabular}{|c|c|c|c|}
\hline \multirow{2}{*}{$\frac{\text { Sigla }}{\text { LSM }}$} & \multirow{2}{*}{$\frac{\text { Composição }}{\mathrm{La}_{1-\gamma} \mathrm{Sr}_{x} \mathrm{MnO}_{3-\delta}}$} & \multicolumn{2}{|c|}{ Condutividade eletrônica $(\mathrm{S} / \mathrm{cm})$} \\
\hline & & $\mathrm{x}=0,5$; & $\sigma=300\left(947^{\circ} \mathrm{C}\right)^{19,20}$ \\
\hline LSF & $\mathrm{La}_{1-x} \mathrm{Sr}_{x}^{\mathrm{x}} \mathrm{FeO}_{3-\delta}^{3-0}$ & $\mathrm{x}=0,2$; & $\sigma=80\left(1000^{\circ} \mathrm{C}\right)^{19,20}$ \\
\hline LSC & $\mathrm{La}_{1-\mathrm{x}}^{1-x} \mathrm{Sr}_{\mathrm{x}}^{\mathrm{x}} \mathrm{CoO}_{3-\delta}^{3-\delta}$ & $\mathrm{x}=0,2$; & $\sigma=10^{3}\left(1000^{\circ} \mathrm{C}\right)^{19,20}$ \\
\hline LSFC & $\mathrm{La}_{1-\mathrm{x}}^{1-x} \mathrm{Sr}_{\mathrm{x}}^{\mathrm{x}} \mathrm{Fe}_{\mathrm{y}} \mathrm{Co}_{1-\mathrm{y}}^{3-0} \mathrm{O}_{3-\delta}$ & $\mathrm{x}=\mathrm{y}=0,2$ & $\sigma=890\left(1000^{\circ} \mathrm{C}\right)^{19,20}$ \\
\hline LSMC & $\begin{array}{l}\mathrm{Ln}_{1-\mathrm{x}} \mathrm{Sr}_{\mathrm{x}} \mathrm{Mn}_{\mathrm{y}} \mathrm{Co}_{1-\mathrm{y}} \mathrm{O}_{3-\delta} \\
\text { onde } \mathrm{Ln}=\mathrm{La}, \mathrm{Pr}, \mathrm{Nd}, \mathrm{Gd}\end{array}$ & $\begin{array}{l}\mathrm{Ln}=\mathrm{La} ; \\
\mathrm{x}=0,2 \mathrm{e}\end{array}$ & \\
\hline LSCF & $\mathrm{La}_{1-\mathrm{x}} \mathrm{Sr}_{\mathrm{x}} \mathrm{Co}_{\mathrm{y}} \mathrm{Fe}_{1-\mathrm{y}} \mathrm{O}_{3-\delta}$ & $\begin{array}{l}y=0,4 ; \\
x=0,2 \text { e } \\
y=0,4 ;\end{array}$ & $\sigma=255\left(1000^{\circ} \mathrm{C}\right)^{19,20}$ \\
\hline LCM & $\mathrm{La}_{1-x} \mathrm{Ca}_{x} \mathrm{MnO}_{3-\delta}$ & $\mathrm{x}=0,1$ & $\sigma=290\left(827^{\circ} \mathrm{C}\right)^{20}$ \\
\hline GSC & $\mathrm{Gd}_{1-x}^{1-x} \mathrm{Sr}_{\mathrm{x}} \mathrm{CoO}_{3-\delta}^{3-0}$ & $\mathrm{x}=0,5$ & $\sigma=5\left(650^{\circ} \mathrm{C}\right)^{20}$ \\
\hline PSC & $\operatorname{Pr}_{1-\mathrm{x}}^{1-x} \mathrm{Sr}_{\mathrm{x}} \mathrm{CoO}_{3-\delta}$ & $\mathrm{x}=0,5$ & $\sigma=10\left(650^{\circ} \mathrm{C}\right)^{20}$ \\
\hline $\mathrm{SCF}$ & $\mathrm{Sr}_{1-\mathrm{x}} \mathrm{Co}_{\mathrm{x}} \mathrm{FeO}_{3-\delta}$ & $\mathrm{x}=0,2$ & $\sigma=10\left(650^{\circ} \mathrm{C}\right)^{20}$ \\
\hline
\end{tabular}

Dos materiais de catodo citados, o que vem sendo mais estudado e que apresenta melhores resultados para altas temperaturas é a LSM (manganita de lantânio dopada com estrôncio - $\mathrm{La}_{1-x} \mathrm{Sr}_{x} \mathrm{MnO}_{3-\delta}$ ), que tem excelente atividade eletrocatalítica para redução do oxigênio à temperatura elevada e é estável nas condições de operação. Além disso, a incorporação de partículas de zircônia, estabilizada com ítria (YSZ), a um eletrodo de LSM aumenta seu desempenho, uma vez que diminui a sobretensão no eletrodo. Este fato torna possível sua aplicação também em pilhas que operam a temperaturas intermediárias (para o caso de temperaturas entre 650 e $\left.800^{\circ} \mathrm{C}\right)^{5,8,22}$. Em função destas características escolhemos este material como exemplo. Apresentamos a seguir as abordagens utilizadas para otimizar suas propriedades, visando sua utilização como material de catodo.

A condutividade eletrônica da LSM é dada pela dopagem com íns divalentes. Esta dopagem promove a retirada de elétrons aumentando a valência de parte dos átomos de manganês de +3 para +4; este processo está associado à substituição de íons $\mathrm{La}^{3+}$ por íons divalentes, tais como estrôncio, bário, níquel, magnésio ou cálcio ${ }^{22}$.

Em atmosferas oxidantes a manganita de lantânio apresenta excesso de oxigênio, mas a quantidade deste excesso varia com a temperatura. Em atmosferas redutoras o material torna-se deficiente em oxigênio. Sob condições muito redutoras a manganita de lantânio dissocia-se em óxido de lantânio $\left(\mathrm{La}_{2} \mathrm{O}_{3}\right)$ e óxido de manganês $\left(\mathrm{MnO}_{2}\right)^{5}$.

O coeficiente de expansão térmica da manganita de lantânio não dopada é de aproximadamente $11,2 \times 10^{-6} \mathrm{~K}^{-1}$. Entretanto, dopando-se a manganita de lantânio com estrôncio $\left(\mathrm{La}_{1-\mathrm{x}} \mathrm{Sr}_{\mathrm{x}} \mathrm{MnO}_{3}\right.$, onde $\mathrm{x}$ varia de 0,05 a 0,30 ) aumenta-se o coeficiente de expansão térmica do material para $12,8 \times 10^{-6} \mathrm{~K}^{-1}$. Assim, o coeficiente de expansão térmica da LSM se torna maior que o do eletrólito de zircônia estabilizada com ítria (YSZ). Para compensar este efeito realiza-se também a substituição de parte dos íons lantânio por cátions menores, tais como cálcio, o que provoca uma diminuição no coeficiente de expansão térmica da manganita de lantânio ${ }^{5,19,22}$.

Atualmente, a pesquisa em novos materiais catódicos tem como principais objetivos a obtenção de materiais que apresentem alta atividade catalítica a temperaturas intermediárias $\left(\mathrm{T}<800^{\circ} \mathrm{C}\right)$ e condutividade elétrica mista (eletrônica e iônica), assim como a otimização da microestrutura do eletrodo e da interface catodo/ eletrólito $^{8,19-22}$.

\section{Anodo}

Os eletrodos anódicos devem ser estáveis em ambientes redutores; ser condutores eletrônicos e, ter porosidade suficiente para permitir o transporte do combustível até a interface eletrólito/eletrodo e o transporte dos produtos da oxidação do combustível para fora do eletrodo ${ }^{1,5,8,15}$. Para facilitar o transporte dos gases, o anodo é fabricado com uma porosidade de $20-40 \%$.

A atmosfera redutora presente no anodo da pilha tipo SOFC permite o uso de um metal, tal como níquel, podendo também ser cobalto, platina, paládio, rutênio ou titânio ${ }^{10,15}$. O níquel apresenta um menor custo se comparado com os outros metais, entretanto, sua expansão térmica é consideravelmente mais alta que a da zircônia estabilizada com ítria (YSZ). O níquel pode também sinterizar na temperatura de operação da pilha, resultando em uma diminuição na porosidade do eletrodo. Esses problemas são evitados através da formação de um esqueleto poroso de YSZ, que envolve as partículas de níquel (cermet de Ni/YSZ). Este esqueleto de YSZ impede a sinterização das partículas de níquel, diminui o coeficiente de expansão térmica do eletrodo e permite melhor adesão entre eletrodo e eletrólito ${ }^{5,8}$.

A condutividade elétrica do cermet $\mathrm{Ni} / \mathrm{YSZ}$ depende da concentração de níquel, sendo que seu comportamento segue uma curva prevista pela teoria de percolação. Este comportamento deve-se à presença de dois mecanismos de condução pelo cermet: uma etapa eletrônica através da fase de níquel e uma etapa iônica através da fase YSZ. O limiar da percolação, para a condutividade, ocorre quando a concentração de níquel é aproximadamente igual a $30 \%$ em volume. Abaixo desta concentração a condutividade do cermet é similar à da YSZ, indicando uma condução iônica através da fase YSZ. Acima desta concentração a condutividade aumenta três ordens de magnitude, correspondendo a uma mudança do mecanismo de condução, que passa a ser eletrônica, através da fase de níquel metálico. Isto é suportado pelo fato da condutividade do cermet $\mathrm{Ni}$ / YSZ, contendo mais que $30 \%$ de níquel em volume, diminuir com o aumento da temperatura, comportamento típico da condução em metais. Além disso, a energia de ativação para a condução passa a ser similar à do níquel puro $(5,38 \mathrm{~kJ} / \mathrm{mol})^{5}$. A condutividade do cermet também depende da microestrutura, sendo que para amostras com um mesmo volume percentual de níquel, um suporte com menor área de superfície tem um melhor revestimento de níquel, o que resulta em maior contato entre as partículas de níquel, proporcionando, assim, maior condutividade para o cermet.

$\mathrm{O}$ principal problema dos anodos tipo cermet Ni/YSZ, em pilhas que fazem uso direto de hidrocarbonetos, está relacionado à deposição de carbono $^{5,8,15}$. Para resolver esse problema estudos recentes utilizam anodos de cermet dos tipos Ru/GDC, Ni/GDC e Cu/ SDC, em temperaturas entre 500 e $800{ }^{\circ} \mathrm{C}^{15,16}$. Uma outra alternativa consiste na utilização de materiais dopados com estrutura tipo perovskita, que contenham metais de transição ( $\mathrm{Fe}, \mathrm{Mn}, \mathrm{Cr}, \mathrm{Ti}, \mathrm{Nb}$ ) e que apresentem condutividade mista (eletrônica e iônica) ${ }^{15,23}$.

\section{Eletrólito}

Eletrólitos sólidos são basicamente condutores iônicos que encontram aplicação não só em pilhas a combustível, mas também em outros dispositivos eletroquímicos como sensores, medidores de oxigênio e baterias.

As vantagens dos eletrólitos sólidos sobre os eletrólitos líquidos, em dispositivos eletroquímicos, podem ser enumeradas: longa vida útil; operação em largas faixas de temperatura, devido a sua alta estabilidade, principalmente no caso dos cerâmicos; possibilidade de miniaturização e, permitir a modulação de suas proprieda- 
des através de seu processamento, principalmente pela síntese química. Tais vantagens tornam estes materiais uma ótima opção para aplicação em pilhas a combustível 1,5,8,24. $^{1,}$

De forma geral, pode-se dizer que existem duas grandes classes de eletrólitos sólidos: os poliméricos e os cerâmicos. Eletrólitos sólidos poliméricos não são estáveis em altas temperaturas e, portanto, não podem ser utilizados em pilhas a combustível de temperatura alta ou intermediária.

Eletrólitos sólidos cerâmicos, por sua vez, são bem mais estáveis e por isso são empregados em dispositivos que atuam em altas temperaturas. Na Tabela 3, são apresentadas as principais famílias de eletrólitos cerâmicos utilizados nesses dispositivos. Cabe ressaltar que estudos recentes têm procurado desenvolver novos materiais condutores iônicos cerâmicos que possam ser utilizados em temperaturas mais baixas, sem que se observe um aumento muito grande em sua resistência elétrica, o que, no caso das pilhas a combustível, permitiria um barateamento do produto final ${ }^{8,24-32}$.

A primeira aplicação de um eletrólito sólido foi feita por Nernst em 1899, a provável composição do sólido utilizado era de $85 \%$ de $\mathrm{ZrO}_{2}$ e $15 \%$ de $\mathrm{Y}_{2} \mathrm{O}_{3}$. Baur e Preis, em 1937, usaram este material em uma pilha a combustível. O mecanismo de condutividade iônica para a zircônia dopada, em termos das vacâncias de oxigênio, foi proposto, em 1943, por Wagner e posteriormente verificado por Hund, em 1952. Entretanto, o aumento do interesse científico por tais materiais começou depois que Kiukola e Wagner, em 1957, demonstraram que zircônia dopada podia ser utilizada como eletrólito sólido em células eltroquímicas ${ }^{25}$.

Na sua forma pura a zircônia não serve como um bom eletrólito, uma vez que sua condutividade iônica é muito baixa. A zircônia estabilizada, especialmente a estabilizada com ítria, é o eletrólito mais utilizado em SOFC, pois possui um adequado nível de condutividade iônica, devido aos íons óxido, e exibe estabilidade em ambas atmosferas, oxidante e redutora, além de apresentar excelentes propriedades mecânicas ${ }^{24-27}$.

À temperatura ambiente, a zircônia pura tem estrutura cristalina monoclínica. A estrutura monoclínica muda para a forma tetragonal acima de $1170{ }^{\circ} \mathrm{C}$ e para a estrutura cúbica acima de $2370{ }^{\circ} \mathrm{C}$. A transformação tetragonal - monoclínica é associada com um aumento do volume da estrutura cristalina (3 a 5\%) 26,27 .

A adição de uma certa quantidade de dopantes estabiliza a estrutura cúbica da zircônia na temperatura ambiente e impede as transições de fase cristalina ${ }^{26}$. Esta estabilização é feita através da substituição de parte dos cátions $\mathrm{Zr}^{4+}$ por cátions divalentes ou trivalentes, de tamanho apropriado. Esta substituição não somente estabiliza a estrutura cúbica, mas também cria vacâncias de oxigênio, de maneira que ocorra a compensação de cargas. Os dopantes mais utilizados são os óxidos de cálcio, de magnésio, de escândio e, principalmente, o óxido de ítrio ${ }^{26}$.

A presença de uma quantidade adequada de vacâncias de oxigênio cria um aumento na mobilidade dos íons óxido na rede, entretanto, uma concentração muito alta de vacâncias acaba provocando uma diminuição desta mobilidade. Conseqüentemente, condutividade elétrica da zircônia estabilizada depende da concentração do dopante e segue o comportamento de Arrhenius, como função da temperatura, sendo independente da pressão de oxigênio ${ }^{26}$.

A zircônia cúbica é preferencialmente utilizada como eletrólito em pilhas do tipo SOFC por ter maior condutividade iônica, se comparada com as zircônias tetragonal ou monoclínica. $\mathrm{O}$ uso da fase cúbica também diminui o problema da transição de fase que ocorre em materiais parcialmente estabilizados, durante a operação da pilha ${ }^{24,26}$.

Eletrólitos baseados em céria $\left(\mathrm{CeO}_{2}\right)$ vem sendo investigados nos últimos 20 anos, com o objetivo de substituição da zircônia estabilizada. Esses materiais têm se mostrados promissores, uma vez que seu uso permitiria um abaixamento da temperatura de operação da pilha, de $1000{ }^{\circ} \mathrm{C}$ para temperaturas em torno de $500{ }^{\circ} \mathrm{C}$, o que proporcionaria maior flexibilidade na escolha de materiais para eletrodos e interconectores, o que tornaria possível uma diminuição no custo total das pilhas tipo $\mathrm{SOFC}^{28}$.

$\mathrm{O}$ dióxido de cério puro é um mau condutor iônico $\left(\sigma_{700^{\circ} \mathrm{C}}=1,9 \mathrm{x}\right.$ $10^{-5} \mathrm{~S} / \mathrm{cm}$ ). No entanto, os valores de condutividade iônica aumentam com a substituição estrutural de $\mathrm{Ce}^{4+}$ por íons metálicos de menor valência, havendo a formação de uma solução sólida entre a céria e o dopante. Há descrições na literatura ${ }^{28-32}$ de céria dopada com vários íons lantanídeos, sendo os mais empregados $\mathrm{Gd}^{3+}$ (GDC)

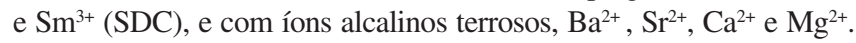
Tais dopagens visam obter um material com maior condutividade iônica em temperatura mais baixa. Por ex., a céria dopada com gadolínio (GDC), $\mathrm{Ce}_{090} \mathrm{Gd}_{010} \mathrm{O}_{195}$, apresenta um valor de condutividade iônica de $\sigma=3,7 \times 10^{-2} \mathrm{~S} / \mathrm{cm}$ a $700{ }^{\circ} \mathrm{C}^{30} \mathrm{e}$, a céria dopada com cálcio(CDC), $\mathrm{Ce}_{0,90} \mathrm{Ca}_{0,10} \mathrm{O}_{1,90}$, de $1,0 \times 10^{-3} \mathrm{~S} / \mathrm{cm}$ a $3900^{\circ} \mathrm{C}^{31}$.

Uma das dificuldades para o emprego da céria dopada, em pilhas a combustível, relaciona-se à redução do íon cério do seu estado de valência (IV) para o de valência (III), na atmosfera redutora do anodo, na faixa de temperatura de operação da pilha. A presença na rede cristalina de uma mistura de íons, do tipo $\mathrm{Ce}^{4+} /$ $\mathrm{Ce}^{3+}$, introduz no material uma apreciável condutividade eletrônica, gerando uma auto descarga elétrica que diminui a eficiência do dispositivo $^{33}$. Para minimizar este efeito tem sido estudado o revestimento do eletrólito de céria com YSZ, assim como o uso de misturas de céria com $Y_{S Z}^{24,34}$, na razão 1:1.

Tabela 3. Famílias mais importantes, composição e condutividade iônica de eletrólitos sólidos usados em pilha a combustível de óxido sólido

\begin{tabular}{|c|c|c|c|}
\hline Família & Composição & Condutividade iôn & $(\mathrm{S} / \mathrm{cm})$ \\
\hline $\mathrm{ZrO}_{2}$ & $\mathbf{Z r}_{1-\mathrm{x}} \mathbf{Y}_{\mathbf{x}} \mathbf{O}_{2-\delta} \operatorname{com} \mathrm{x}=0,08-0,10$ & $\mathrm{x}=0,08$ & $\sigma=1,0 \times 10^{-1}\left(1000{ }^{\circ} \mathrm{C}\right)^{26,27}$ \\
\hline $\mathrm{CeO}_{2}$ & $\mathbf{C e}_{1-\mathrm{x}}^{1-\mathrm{x}} \mathbf{M}_{\mathbf{x}}^{\mathbf{x}} \mathbf{O}_{2-\mathrm{x}}$ onde $\mathrm{M}=\mathrm{Ga}^{3+}, \mathrm{Eu}^{3+}, \mathrm{Gd}^{3+}, \mathrm{Sm}^{3+}$, & $\mathrm{x}=0,1$ & \\
\hline & $\mathrm{La}^{3+}, \mathrm{Ba}^{2+}, \mathrm{Sr}^{2+}$ e $\mathrm{Ca}^{2+}$ & $\mathrm{M}=\mathrm{Gd}^{3+}$ & $\sigma=3,7 \times 10^{-2}\left(700^{\circ} \mathrm{C}\right)^{30}$ \\
\hline & & $\mathrm{M}=\mathrm{Ca}^{2+}$ & $\sigma=1,0 \times 10^{-3}\left(390^{\circ} \mathrm{C}\right)^{31}$ \\
\hline & $\mathrm{Ce}_{1-\mathbf{x}} \mathbf{M}_{\mathbf{x}} \mathbf{B i}_{\mathbf{0}, 4} \mathbf{O}_{2,6-\mathbf{x}}$ onde $\mathrm{M}=\mathrm{Ba}^{2+}, \mathrm{Sr}^{2+} \mathrm{e} \mathrm{Ca}^{2+}$ & $\begin{array}{l}\mathrm{x}=0,05 \\
\mathrm{M}=\mathrm{Ca}^{2+}\end{array}$ & $\sigma=1,7 \times 10^{-2}\left(600^{\circ} \mathrm{C}\right)^{32}$ \\
\hline BIMEVOX & $\mathbf{B i}_{2} \mathbf{V}_{1-\mathbf{x}} \mathbf{M}_{\mathbf{x}} \mathbf{O}_{5,5-1,5 \mathrm{y}}$ onde $\mathrm{M}=\mathrm{Co}^{2+}, \mathrm{Sb}^{+5}, \mathrm{Cu}^{2+}$, & $\mathrm{x}=0,1 ; \mathrm{M}=\mathrm{Co}^{2+}$ & $\sigma=1,0 \times 10^{-3}\left(300{ }^{\circ} \mathrm{C}\right)^{36,37}$ \\
\hline & $\mathrm{Fe}^{2+}, \mathrm{Fe}^{3+}, \mathrm{Nb}^{5+}, \mathrm{Mn}^{2+}, \mathrm{Mn}^{3+}, \mathrm{Ba}^{2+}, \mathrm{Ca}^{2+}, \mathrm{Ti}^{4+}$ & $\mathrm{M}=\mathrm{Sb}^{5+}$ & $\sigma=3,0 \times 10^{-3}\left(300^{\circ} \mathrm{C}\right)^{36,37}$ \\
\hline & & $\mathrm{M}=\mathrm{Cu}^{2+}$ & $\sigma=1,0 \times 10^{-2}\left(350^{\circ} \mathrm{C}\right)^{37}$ \\
\hline & & $\mathrm{M}=\mathrm{Fe}^{3+}$ & $\sigma=1,0 \times 10^{-3}\left(300^{\circ} \mathrm{C}\right)^{38}$ \\
\hline LSGM & $\mathrm{La}_{1-\mathrm{x}} \mathrm{Sr}_{\mathrm{x}} \mathrm{Ga}_{1-\mathrm{y}} \mathrm{Mg}_{\mathrm{y}} \mathrm{O}_{3-\delta}$ & $\mathrm{x}=0.2 ; \mathrm{y}=0,17$ & $\sigma=1,7 \times 10^{-1}\left(800^{\circ} \mathrm{C}\right)^{24}$ \\
\hline LAMOX & $\begin{array}{l}\mathbf{L a}_{2-\mathrm{x}} \mathbf{M}_{\mathbf{x}} \mathbf{M o}_{2-\mathrm{y}} \mathbf{N}_{\mathbf{y}} \mathbf{O}_{9-\delta} \text { onde } \mathrm{N}=\mathrm{Re}, \mathrm{W}, \mathrm{Cr}, \mathrm{V} \text { e } \\
\mathrm{M}=\mathrm{Sr}^{2+}, \mathrm{Ba}^{2+}, \mathrm{K}^{1+}, \mathrm{Bi}^{3+}, \mathrm{Gd}^{3+}\end{array}$ & $\mathrm{x}=0,0 ; \mathrm{y}=0,0$ & $\sigma=3,0 \times 10^{-2}\left(720^{\circ} \mathrm{C}\right)^{41}$ \\
\hline
\end{tabular}


Uma outra classe de eletrólitos sólidos inorgânicos consiste na família denominada BIMEVOX, formada por compostos derivados do $\mathrm{Bi}_{4} \mathrm{~V}_{2} \mathrm{O}_{11}$ por substituição parcial do vanádio com uma variedade de metais ${ }^{35,36}$. A fase $\mathrm{Bi}_{4} \mathrm{~V}_{2} \mathrm{O}_{11}$ pode ser obtida a partir da solução sólida de $2 \mathrm{Bi}_{2} \mathrm{O}_{3}-\mathrm{xV}_{2} \mathrm{O}_{5}$ onde $0,86 \leq \times \leq 1$, e exibe duas transições de fase reversíveis, $\alpha \leftrightarrow \beta \leftrightarrow \gamma$, a 450 e $580{ }^{\circ} \mathrm{C}$, respectivamente ${ }^{36}$.

Estudos para estabilizar a fase gama em temperaturas mais baixas levaram à obtenção da família BIMEVOX. Nesta família a substituição parcial do $\mathrm{V}^{5+}$ por cátions iso ou aliovalentes leva à estabilização da estrutura gama. Tais compostos são representados pela fórmula $\mathrm{Bi}_{2} \mathrm{~V}_{1-\mathrm{x}} \mathrm{Me}_{\mathrm{x}} \mathrm{O}_{5,5-\mathrm{y}}$ onde $0 \leq x \leq 1 \mathrm{e} \mathrm{Me}=$ cátion metálico $^{36-39}$. Para esta classe de materiais, os melhores resultados de condutividade foram obtidos nas substituições com $\mathrm{Co}^{2+}, \mathrm{Cu}^{2+}$ e $\mathrm{Fe}^{3+}$ (Tabela 3).

Devido à sua baixa estabilidade em atmosfera redutora, onde ocorre a redução dos íons $\mathrm{V}^{5+}$ e $\mathrm{Bi}^{3+}$, levando à formação de $\mathrm{Bi}$ metálico e $\mathrm{V}_{2} \mathrm{O}_{3}{ }^{39}$, estes materiais têm sido aplicados principalmente como membranas para separação de oxigênio ${ }^{35-39}$. Para tornar possível sua aplicação em pilhas tipo SOFC algumas estratégias têm sido desenvolvidas, como por ex., a adição de alumina ou zircônia altamente dispersa, visando melhorar sua estabilidade química e propriedades mecânicas ${ }^{35}$.

Outras duas famílias de condutores iônicos inorgânicos vêm recebendo considerável atenção recentemente, uma delas é a LSGM ${ }^{40}$ e a outra, $\mathrm{LAMOX}^{41}$; o grande problema com relação à aplicação desses materiais reside também na baixa estabilidade química em atmosferas redutoras ${ }^{24}$. Para contornar este problema, no caso da família LSGM, alguns pesquisadores utilizam camadas finas protetoras de óxido de cério e vem testando novos anodos à base de cobre $^{40}$.

\section{Métodos de obtenção dos componentes}

Os diferentes componentes de uma pilha tipo SOFC são manufaturados através de uma variedade de técnicas. Faremos aqui uma breve exposição dos métodos comerciais mais usados ${ }^{8,17,42}$.

Os filmes finos (30-150 $\mu \mathrm{m})$ e uniformes de eletrólito cerâmico são geralmente obtidos pelas técnicas de "tape casting" e "tape calendering".

Na técnica de "tape casting" é feita a deposição de um filme cerâmico sobre um suporte temporário, que consiste em uma folha móvel. Várias camadas podem ser depositadas, sobre a superfície da primeira camada, para produzir um eletrólito auto suportado; após a remoção do suporte e da evaporação do dispersante, a fita do eletrólito pode ser aquecida.

No método de "tape calendering" a espessura do filme é controlada pelo espaçamento entre rolos. $\mathrm{O}$ catodo e o anodo podem ser submetidos a um tratamento térmico conjuntamente com um eletrólito obtido por esta técnica. Há de se ressaltar que para este procedimento o coeficiente de expansão térmica dos três componentes deve ser similar.

Anodos e catodos podem ser depositados sobre o eletrólito, com melhor desempenho, via o processo de "slurry-coating". Neste método, primeiro é feita uma suspensão do pó do material em água, a seguir é realizada a cobertura do substrato (eletrólito) com esta suspensão e depois da secagem é feita a sinterização.

Outro método consiste no "screen printing", utilizado para produzir camadas densas e porosas com espessura da ordem de poucos $\mu \mathrm{m}$ até cerca de $15 \mu \mathrm{m}$. Normalmente, o pó contendo os componentes necessários é misturado com um plastificante e um ligante orgânico, então a pasta é colocada em uma tela e sua passagem é forçada por um rolo de borracha. A espessura do filme é determinada pela espessura da tela de arame. O filme então é seco e sinterizado. Um dos problemas mais comuns desse método é a ocorrência de trincas.

A deposição eletroquímica por vapor (EVD) é freqüentemente usada para produzir montagens suportadas pelo catodo, como no caso das pilhas SOFC tipo tubular da Siemens-Westinghouse. Nesses casos, o eletrólito é depositado a altas temperaturas e sob baixa pressão, na forma de filme, sobre um catodo poroso. Esta técnica consiste em uma variação do processo de deposição química por vapor e é utilizada especificamente em casos em que há a necessidade de se depositar, sobre um substrato poroso, um filme impermeável a gases, ou seja, que não permita a mistura entre o oxidante e o combustível. A formação de um filme denso, através do processo EVD, ocorre em duas etapas. Na primeira, obtém-se o fechamento dos poros do substrato através da reação direta de um cloreto metálico gasoso com vapor de água. Para que isto ocorra os reagentes são introduzidos de lados opostos do substrato poroso e se difundem através dos poros, de maneira que estes passam a agir como sítios de reação para a deposição do óxido. Na segunda etapa, o processo de crescimento do filme ocorre através de um mecanismo eletroquímico, no qual se observa uma difusão no estado sólido de íons oxigênio através do óxido depositado. Durante o processo de EVD o óxido depositado apresenta condução eletrônica e iônica, permitindo o transporte de íons oxigênio e de elétrons, em sentidos opostos, o que preserva a eletroneutralidade do filme de óxido durante seu crescimento ${ }^{42}$. Filmes de eletrólitos depositados por esta técnica possuem boa homogeneidade e excelentes qualidades mecânicas, entretanto, esta técnica apresenta a desvantagem de ter um alto custo, o que encarece o preço das pilhas SOFC do tipo tubular, limitando sua aplicação.

As técnicas de deposição química por vapor e deposição por vapor assistida por chama, conjuntamente com técnicas de "sputtering" também podem ser utilizadas para realizar a deposição por camada dos componentes de uma SOFC. Outras técnicas, de menor custo, usadas para obter filmes do anodo em cima do filme do eletrólito, são o "dry spraying" e o "powder spraying", enquanto que o "vacuum plasma spraying" é rotineiramente usado para depositar camadas do catodo ou do anodo em cima do eletrólito $^{8,17,42}$.

\section{CONCLUSÕES E PERSPECTIVAS}

Como foi exposto, a aplicação prática de sistemas de pilhas a combustível envolve um intrincado conjunto de problemas científicos e tecnológicos, que passam pela compreensão dos processos químicos da pilha, pela modelagem química dos seus componentes, pela manufatura destes e pelo projeto do formato da pilha. Cabe ressaltar que também é fundamental que se faça uma avaliação do custo total do processo. Devido ao grande interesse comercial, numerosos grupos de pesquisa e inúmeras companhias têm atuado no seu desenvolvimento nos últimos 20 anos. As interações entre estes grupos e os investimentos nesta área serão decisivas para desenvolvimento e implementação prática desta tecnologia.

A pilha a combustível do tipo óxido sólido mostra-se promissora, principalmente, para a geração de energia em módulos estacionários, desde poucos $\mathrm{kW}$ até dezenas de MW, pois apresenta uma característica interessante que consiste na flexibilidade de combustível, podendo ser operada com hidrocarbonetos pré-reformados ou não, além de poder apresentar a co-geração de calor. Vários estudos têm investigado também a potencialidade das pilhas tipo SOFC para aplicações em transporte; algumas companhias estão desenvolvendo pilhas tipo SOFC como unidades auxiliares de força para veículos movidos a hidrocarbonetos ${ }^{1,8,16,43}$, como por ex., gasolina, e mais recentemente para aplicações portáteis ${ }^{13}$. 


\section{AGRADECIMENTOS}

Ao Conselho Nacional de Desenvolvimento Científico e Tecnológico - CNPq pelo apoio financeiro.

\section{REFERÊNCIAS}

1. Willians, M. C.; Fuel Cell Handbook, $6^{\text {th }}$ ed., U. S. Department of Energy: West Virginia, EG\&G Technical Services, Inc.; 2002.

2. Dresselhaus, M. S.; Thomas, I. L.; Nature 2001, 414, 332; Antonucci, V.; Antonucci, P. L.; Gullo, L.; Rosa, D. L.; Siracusano, S.; J. Eur. Ceram. Soc. 2004, 24, 1337.

3. Wendt, H.; Götz, M.; Linardi M.; Ouim. Nova 2000, 23, 538; Wedt, H.; Linardi M.; Aricó, E. M.; Quim. Nova 2002, 25, 470; Villullas, H. M.; Ticianelli, E. A.; Gonzáles, E. R.; Química Nova na Escola 2002, 15, 28.

4. http://www.fuelcells.org, acessada em Setembro 2004.

5. Minh, N. Q.; J. Am. Ceram. Soc. 1993, 76, 563; McIntosh, S.; Gorte, R. J.; Chem. Rev. 2004, 104, 4845.

6. Vielstich, W.; J. Braz. Chem. Soc. 2003, 14, 503.

7. Grove, W. R.; Phil. Mag. Scr. 1839, 314, 127.

8. Yamamoto, O.; Electrochim. Acta 2000, 45, 2423; Steele, B. C. H.; Solid State Ionics 2000, 134, 3; Singhal, S. C.; Solid State Ionics 2000, 135, 305; Carrete, L.; Friedrich, K. A.; Stimming, U.; Fuel Cells 2001, 1, 5; Steele, B. C. H.; J. Mater. Sci. 2001, 36, 1053; Tiffée, E. I.; Weber, A.; Herbstritt, D.; J. Eur. Ceram. Soc. 2001, 21, 1805; Huijsmans, J. P. P.; Curr. Opin. Solid State Mater. Sci. 2001, 5, 317; Singhal, S.C.; Solid State Ionics 2002, 152-153, 405; Minh, N. Q.; Solid State Ionics 2004, 174, 271.

9. Roos, M.; Batawi, E.; Harnisch, U.; Hocker, T.; J. Powder Sources 2003 , 118,86 .

10. Badwal, S. P. S.; Solid State Ionics 2001, 143, 39; Zhu, W. Z.; Deevi, S. C.; Mater. Sci. Eng., A 2003, 348, 227; Fergus, J. W.; Solid State Ionics 2004, 171, 1; Wincewicz, K. C.; Cooper, J. S.; J. Power Sources 2005, 140, 280.

11. Hibino, T.; Wang, S. Q.; Kakimoto, S.; Sano, M.; Electrochem. Solid-State Lett. 1999, 2, 317; Hibino, T.; Kuwahara, Y.; Wang, S.; J. Electrochem. Soc. 1999, 146, 2821; Hibino, T.; Wang, S.; Kakimoto, S.; Sano, M.; Solid State Ionics 2000, 127, 89. Hibino, T.; Tsunekawa, H.; Tanimoto, S; Sano, M; J. Electrochem. Soc. 2000, 147, 1338; Hibino, T.; Hashimoto, S.; Inoue, T.; Tokuno, J.; Yoshida, S.; Sano, M.; J. Electrochem. Soc. 2000, 147, 2888; Hibino, T.; Hashimoto, A.; Inoue, T.; Tokuno, J.; Yoshida, S.; Sano, M.; Science 2000, 288, 2031; Hibino, T.; Hashimoto, A.; Suzuki, M.; Yano, M.; Yoshida, S.; Sano, M.; J. Electrochem. Soc. 2002, 149, 195; Napporn, T. W.; Morin, F.; Meunier, M.; Electrochem. Solid-State Lett. 2004, 7, 60; Stefan, I. C.; Jacobson, C. P.; Visco, S. J.; De Jonghe, L. C.; Electrochem. Solid-State Lett. 2004, 7, 198 ; Suzuki, T.; Jasinki, P.; Anderson, H. U.; Dogan, F.; J. Electrochem. Soc. 2004, 151, 1678; Tomita, A.; Hirabayashi, D.; Hibino, T.; Nagao, M.; Sano, M.; Electrochem. Solid-State Lett. 2005, 8, 63; Suzuki, T.; Jasinki, P.; Petrovsky, V.; Anderson, H. U.; Dogan, F.; J. Electrochem. Soc. 2005, 152, 527.

12. Haile, S. M.; Acta Mater. 2003, 51, 5981; Haile, S. M.; Mater. Today 2003, March, 24; Shao, Z.; Kwak, C.; Haile, S. M.; Solid State Ionics 2004, 175, 39; Shao, Z.; Haile, S. M.; Nature 2004, 431, 170.

13. Shao, Z.; Haile, S. M.; Ahn, J.; Ronney, P. D.; Zhan, Z.; Barnett, S. A.; Nature 2005, 435, 795 .

14. Eyraud, C.; Lenoir, J.; Géry, M.; C. R. Acad. Sci. Paris 1961, 252, 1599; Priestnall, M. A.; Kotzeva, V. P.; Fish, D. J.; Nilsson, E. M.; J. Power Sources 2002, 106, 21.

15. Atkinson, A.; Barnett, S.; Gorte, R. J.; Irvine, J. T. S.; Mcevoy, A. J.; Mogensen, M.; Singhal, S. C.; Vohs, J.; Nature Mater. 2004, 3, 17; Jiang, S. P.; Chan, S. H.; J. Mater. Sci. 2004, 39, 4405.

16. Xia, C.; Liu, M.; Solid State Ionics 2002, 152, 423; Kim, H.; Lu, C.; Worrell, W. L.; Vohs, J. M.; Gorte, R. J.; J. Eletrochim. Soc. 2002, 149, 247; Hibino, T.; Hashimoto, A.; Yano, M.; Suzuki, M.; Sano, M.; Electrochim. Acta 2003, 48, 2531; Lu, C.; Worrell, W. L.; Vohs, J. M.; Gorte, R. J.; J. Eletrochim. Soc. 2003, 150, 1357; Okawa, Y.; Hirata, Y.; J. Eur. Ceram. Soc. 2005, 25, 473; Zhan, Z.; Barnett, S. A.; Science 2005, $308,844$.

17. Steele, B. C. H.; Heinzel, A.; Nature 2001, 414, 345; Tietz, F.; Buchkremer, H. P.; Stöver, D.; Solid State Ionics 2002, 152-153, 373; Brandon, N. P.; Skinner, S.; Steele, B. C. H.; Annu. Rev. Mater. Res. 2003, 33, 183.

18. Murray, E. P.; Tsai, T.; Barnett, S. A.; Nature 1999, 400, 649; Park, S.; Vohs, J. M.; Gorte, R. L.; Nature 2000, 404, 265.

19. Florio, D. Z.; Fonseca, F. C.; Muccillo, E. N. S.; Muccillo, R.; Cerâmica 2004, 50, 275

20. Skinner, S. J.; Int. J. Inorg. Mater. 2001, 3, 113; Ricoult, M. B.; Trichet, M. F.; Solid State Ionics 2002, 150, 143; Simner, S. P.; Bonnett, J. R.;
Canfield, N. L.; Meinhardt, K. D.; Shelton, J. P.; Sprenkle, V. L.; Stevenson, J. W.; J. Powder Sources 2003, 113, 1; Mamak, M.; Métraux, G. S.; Petrov, S.; Coombs, N.; Ozin, G. A.; Green, M. A.; J. Am. Chem. Soc. 2003, 125, 5161; Adler, S. B.; Chem. Rev. 2004, 104, 4791; Badwal, S. P. S.; Forger, K.; Mater Forum 1997, 21, 187; Tai, L. W.; Nasrallah, M. M.; Andreson, H. U.; Sparlin, P. M.; Sahlin, S. R.; Solid State Ionics 1995, 76, 259; Shuk, P.; Tichonova, L.; Guth, U.; Solid State Ionics 1994, 68, 177; Ralph, J. M.; Rossignol, C.; Bae, J. M.; Vaughey, J. T.; Solid State Ionics 2004, 175, 59.

21. Chiba, R.; Yoshimura, F.; Sakurai, Y.; Solid State Ionics 2002, 152, 575; Qiu, L.; Ichikawa, T.; Hirano, A.; Imanishi, N.; Takeda, Y.; Solid State Ionics 2003, 158, 55; Kato, H.; Kudo, T.; Naito, H.; Yugami, H.; Solid State Ionics 2003, 159, 217

22. Jiang, S. P.; J. Powder Sources 2003, 124, 390; Jiang, S. P.; Love, J. G.; Solid State Ionics 2003, 158, 45; Chen, X. J.; Khor, K. A.; Chan, S. H.; Solid State Ionics 2004, 167, 379; Gaudon, M.; Robert, C. L.; Ansart, F.; Dessemond, L.; Stevens, P.; J. Powder Sources 2004, 133, 214; Haanappel, V. A. C.; Mertens, J.; Rutenbeck, D.; Tropartz, C.; Herzhof, W.; Sebold, D.; Tietz, F.; J. Powder Sources 2005, 141, 216; Ji, Y.; Kilner, J. A.; Carolan, M. F.; Solid State Ionics 2005, 176, 937.

23. Tao, S.; Irvine, J. T. S.; Solid State Ionics 2003, 159, 159; Tao, S.; Irvine, J. T. S.; Nature Mater. 2003, 2, 320.

24. Boivin, J. C.; Mairesse, G.; Chem. Mater. 1998, 10, 2870; Goodenough, J. B.; Nature 2000, 404, 821; Kilner, J. A.; Solid State Ionics 2000, 129, 13; Adachi, G.; Imanaka, N.; Tamura, S.; Chem. Rev. 2002, 102, 2405; Goodenough, J. B.; Annu. Rev. Mater. Res. 2003, 33, 91; Skinner, S. J.; Kilner, J. A.; Mater. Today 2003, March, 30; Karton, V. V.; Marques, F. M. B.; Atkinson, A.; Solid State Ionics 2004, 174, 135; Mogensen, M.; Lybye, D.; Bonanos, N.; Hendriksen, P. V.; Poulsen, F. W.; Solid State Ionics 2004, 174, 279.

25. Knauth, P.; Tuller, H. L.; J. Am. Ceram. Soc. 2002, 85, 1654

26. Stevens, R.; An Introduction to Zirconia, $2^{\text {nd }}$ ed., Magnesium Elektron Ltda: U.K., 1986.

27. Badwal, S. P. S.; Foger, K.; Ceram. Int. 1996, 22, 257.

28. Inaba H.; Tagawa H.; Solid State Ionics 1996, 83, 1; Steele, B. C. H.; Solid State Ionics 2000, 129, 95; Mogensen, M.; Sammes, N. M.; Tompsett, G. A.; Solid State Ionics 2000, 129, 63; Rocha, R. A.; Muccillo, E. N. S.; Cerâmica 2001, 47, 219; Lu, C.; Worrell, W. L.; Gorte, R. J.; Vohs, J. M.; J. Electrochem. Soc. 2003, 150, 354.

29. Shuk, P.; Greenblatt, M.; Croft, M.; J. Alloys Compd. 2000, 303, 465; Zhu, B.; Liu, X.; Sun, M.; Ji, S.; Sun, J.; Solid State Sci. 2003, 5, 1127; Rodriguez, J. A.; Wang, X.; Hanson, J. C.; Liu, G.; Iglesias-Juez, A.; Fernández-Garcia, M.; J. Chem. Phys. 2003, 119, 5659.

30. Herle, J. V.; Sineviratne, D.; McEvoy, A. J.; J. Eur. Ceram. Soc. 1999, 19, 837.

31. Malta, L. F. B.; Medeiros, M. E.; Tsuneharu, O.; J. Therm. Anal. Cal. 2004, 75, 901; Malta, L. F. B.; Medeiros, M. E.; Tsuneharu, O.; J. Eur. Ceram. Soc., submetido.

32. Zhao, H.; Feng, S. H.; Chem. Mater. 1999, 11, 958; Wang, F. Y.; Chen, S.; Wang, Q.; Yu, S.; Cheng, S.; Catal. Today 2004, 97, 189.

33. Doshi, R.; Richards, V. L.; Carter, J. D.; Wang, X.; Krumpelt, M.; J. Electrochem. Soc. 1999, 146, 1273.

34. Sammes, N. M.; Tompsett, G. A.; Mogensen, M.; Solid State Ionics 2000 $129,63$.

35. Steil, M. C.; Fouletier, J.; Kleitz, M.; Labrune, P.; J. Eur. Ceram. Soc. 1999, 19, 815; Steil, M. C.; Fouletier, J.; Kleitz, M.; Lagrange, G.; Del Gallo, P.; Mairesse, G.; Boivin, J. C.; US pat. 6,207,038 2001

36. Abrahan, F.; Mairesse, G.; Nowogrocki, G.; Debreville-Gresse, M. F.; Solid State Ionics 1988, 28/30, 529; Abrahan, F.; Boivin, J. C. ; Mairesse, G.; Nowogrocki, G.; Solid State Ionics 1990, 40/41, 934; Vannier, R. N.; Abrahan, F.; Mairesse, G.; Nowogrocki, G.; Solid State Ionics 1992, 53/ 56, 713; Joubert, O.; Jouanneaux, A.; Ganne, M.; Mater. Res. Bull. 1994, 29, 175; Vannier, R. N.; Abrahan, F.; Mairesse, G.; Nowogrocki, G.; Solid State Ionics 1995, 80, 11; Lazure, S.; Vernochet, C.; Vannier, R. N.; Nowogrocki, G.; Mairesse, G.; Solid State Ionics 1996, 90, 117; Kim, N.; Grey, C. P.; Science 2002, 297, 1317; Xia, C.; Liu, M.; Adv. Mater. 2002, 14, 521; Hervoches, C. H.; Steil, M. C.; Muccillo, R.; Solid State Sci. 2004, $6,173$.

37. Sharma, V.; Shukla, A. K.; Gopalakrishman, J.; Solid State Ionics 1992 , 58, 359; Vannier, R. N.; Abrahan, F.; Mairesse, G.; Nowogrocki, G.; J. Solid State Chem. 1993, 103, 441; Krok, F.; Bogusz, W.; Jakubowski, W.; Dygas, J. R.; Banyobango, D.; Solid State Ionics 1994, 70/71, 211; Anne, M.; Pernot, E.; Abrahan, F.; Mairesse, G.; Strobel, P.; Bacmann, M.; Fouletier, J.; Vannier, G.; Solid State Ionics 1994, 70/71, 259; Breiter, M. W.; Dygas, J. R.; Kurek, P.; Electrochim. Acta 1995, 40, 1545; Vannier, R. N.; Abrahan, F.; Mairesse, G.; Nowogrocki, G.; Solid State Ionics 1994, 70/71, 248.

38. Silva, T. L. S.; Malta, L. F. B.; Medeiros, M. E.; Resumos da $21^{a}$ Reunião da Sociedade Brasileira de Química, Poços de Caldas, Brasil, 1998; García- 
González, E.; Arribas, M.; González-Calbet, J. M.; Chem. Mater. 2001, 13 96; Amado, R. S.; Mercês, P. S.; Malta, L. F. B.; Medeiros, M. E.; Resumos da $26^{a}$ Reunião da Sociedade Brasileira de Química, Poços de Caldas, Brasil, 2003; Malta, L. F. B.; Medeiros, M. E.; Resumos da $26^{a}$ Reunião da Sociedade Brasileira de Química,Poços de Caldas, Brasil, 2003; Malta, L. F. B.; Medeiros, M. E.; J. Therm. Anal. Calorim., 2005, 81, 149.

39. Delmaire, F.; Rigole, M.; Zhilinskaya, E. A.; Aboukais, A.; Hubaut, R.; Mairesse, G.; Phys. Chem. Chem. Phys. 2000, 2, 4477; Patoux, S.; Vannier, R. S.; Mairesse, G.; Nowogrocki, G.; Tarascon, J. M.; Chem. Mater. 2001, 13, 500; Guillodo, M.; Fouletier, J.; Dessemond, L.; Del Gallo, P.; Eletrochim. Acta 2002, 47, 2809; Tikhonovich, V. N.; Naumovich, E. N.; Kharton, V. V.; Yaremchenko, A. A.; Kovalevsky, A. V.; Vecher, A. A.; Eletrochim. Acta 2002, 47, 3957; Pirovano, C.; Vannier, R. N.; Mairesse, G.; Nowogrocki, G.; Boivin, J. C.; Solid State Ionics 2003, 159, 181; Vannier, R. N.; Skinner, S. J.; Chater, R. J.; Kilner, J. A.; Mairesse, G.; Solid State Ionics 2003, 160, 85; Vannier, R. N.; Chater, R. J.; Skinner, S. J.; Kilner, J. A.; Mairesse, G.; Solid State Ionics 2003, 160, 327; Chetouani, A.; Taouk, B.; Richard, E. B. Aad, E. A.; Aboukaïs, A.; Appl. Catal., A 2003, 252, 269; Capoen, E.; Steil, M. C.; Tancret, N.; Nowogrocki, G.; Boivin, J. C.; Mairesse, G.; Vannier, R. N.; Anne, M.; Isnard, O.; Solid State Ionics 2004, 175, 419.

40. Feng, M.; Goodenough, J. B.; Eur. J. Solid State Inorg. Chem. 1994, 31, 663. Ishihara, T.; Matsuda, H.; Takita, Y.; J. Am. Chem. Soc. 1994, 116
3801; Kharton, V. V.; Yaremchenko, A. A.; Viskup, P. A.; Mather, G. C.; Naumovich, E. N.; Marques, F. M. B.; Solid State Ionics 2000, 128, 79; Huang, H. Q.; Wang, J. H.; Goodenough, J. B.; J. Eletrochem. Soc. 2001, 148, 788; Zhang, X. G.; Ohara, S.; Okawa, H.; Maric, R.; Fukui, T.; Solid State Ionics 2001, 139, 145; An, S.; Lu, C.; Worrell, W. L.; Gorte, R. J.; Vohs, J. M.; Solid State Ionics 2004, 175, 135; Yi, J. Y.; Choi, G. M.; Solid State Ionics 2004, 175, 145; He, T.; Guan, P.; Cong, L.; Ji, Y.; Sun, H.; Wang, J.; Liu, J.; J. Alloys Compd. 2005, 393, 292; Wan, J. H.; Yan, J. Q.; Goodenough, J. B.; J. Eletrochem. Soc. 2005, 152, 1511.

41. Lacorre, Ph.; Goutenoire, F.; Bohnke, O.; Retoux, R.; Laligant, Y.; Nature 2000, 404, 856; Goutenoire, F.; Isnard, O.; Retoux, R.; Lacorre, Ph; Chem. Mater. 2000, 12, 2575; Goutenoire, F.; Isnard, O.; Suard, E.; Bohnke, O.; Laligant, Y.; Retoux, R.; Lacorre, Ph.; J. Mater. Chem. 2001, 11, 119; Georges, S.; Skinner, S. J.; Lacorre, P.; Steil, M. C.; Dalton Trans. 2004, 19, 3101; Lopez, D. M.; Morales, J. C. R.; Coll, D. P.; Nunez, P.; Abrantes, J. C. C.; Frade, J. R.; J. Solid State Eletrochem. 2004, 8, 638.

42. Will, J.; Mitterdorfer, A.; Kleinlogel, C.; Perednis, D.; Gauckler, L. J.; Solid State Ionics 2000, 131, 79; Choy, K. L.; Prog. Mater. Sci. 2003, 48, 57; Liu, Y.; Liu, M.; Adv. Mater. 2003, 16, 256; Liu, Y.; Zha, S.; Liu, M.; Chem. Mater. 2004, 16, 3502.

43. http://www.fuelcellseminar.com/pdf/2005/Tuesday-Nov15/ Bosch_Russ_PlenaryI.PDF, acessada em Fevereiro 2006. 